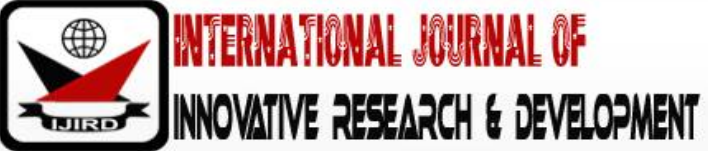

ISSN 2278 - 0211 (Online)

\section{Preparedness for Disaster Risk Management by Rescue Service Teams in Nairobi County, Kenya}

Evans Nyaberi kiage
Student, Department of Emergency Management Studies,
Masinde Muliro University of Science and Technology, Kenya
Dr. Ferdinand Nabiswa
Lecturer, Department of Emergency Management Studies
Masinde Muliro University of science and technology, Kenya
Dr. Omukaka O. Panyako
Lecturer, Department of Building and Construction
Technical University of Kenya, Kenya

\begin{abstract}
:
Disaster preparedness involves the education and training of officials and the population at risk, the training of intervention teams, and the establishment of policies, standards, organizational arrangements and operational plans to be applied following a disaster. This study sought to establish the level of preparedness for disaster risk management by the rescue service teams in Nairobi County. The study adopted descriptive survey as the research design guiding the study. The target population of this study comprised 1398 officers drawn from the National police officers, Paramedics, the fire brigade, the Red Cross society as well as officers from the interior ministry represented by the National Disaster management Unit (NDMU). The research used stratified random sampling and simple random sampling. The researcher used a structured questionnaire as the main data collection instrument. The analysis of quantitative data was through descriptive statistics after being coded and keyed into Statistical Packages for Social Scientists (SPSS Version 21). The study used measures of central tendency and dispersion, absolute and relative percentages, and frequencies for descriptive statistics. The study established that the rescue teams comply with the disaster management policies to a very great extent. The study also established that there was high level of disaster management training for effective disaster preparedness by rescue service teams in Nairobi County and that the level of disaster management equipment available among rescue service teams in Nairobi County was very high. The compliance with the disaster management policies is a necessary step towards achieving better results in this area. The study deduces that disaster management equipment influences the disaster preparedness in the institutions. The study recommended that there is need to enhance the disaster management policies in order to create awareness of disaster preparedness and long-term mitigation and strengthen disaster management institutions to great extents
\end{abstract}

Keywords: Preparedness, disaster, disaster risk management, rescue service teams, compliance, disaster management policies, disaster management training, disaster management equipment

\section{Introduction}

All over the world, disasters have wreaked havoc to developmental gains spanning for many years in the history of many countries. For many ordinary people who live and work in many countries, Kenya included, disasters have made life to be very difficult for them. Social, economic and political posterity has been compromised with each emergency or disaster bedeviling the society. Even those fortunate persons who have modest means of livelihood find it hard to feed, clothe and shelter their families in the event of a disaster (Halimu, 2017). As the world advances technologically and otherwise, it is disturbing to note that the number of people at risk of disasters has been growing by 70 to 80 million per year (UN, 2012).

Disasters are severe disruptions, psychological and psychosocial, which greatly exceed the coping capacity of the affected communities. A disaster could be an event or series of events, which give rise to casualties and/ or damage or loss of property, infrastructure, essential services or means of livelihoods on a scale which is beyond the normal capacity of the affected community to cope with unaided. This disruption may create more difficulties than the physical consequences (Quarantelli, 2010). Disaster preparedness involves forecasting and taking precautionary measures prior to an imminent threat when advance warnings are possible. Effective plans also consider securing resources, possibly including stockpiling supplies and earmarking funds. The magnitude of a disaster depends on the characteristics, the probability and intensity of the hazard and the susceptibility of exposed elements based on the prevailing physical, social and 
environmental conditions (Paul, 2012). Preparedness for the first and immediate response is called emergency preparedness.

In Africa, lack of preparedness and incorporation of ineffective plans into the disaster management agenda have been blamed for inadequate and ineffective emergency response by rescue service teams (Findley, 2012). This unpreparedness has been an issue across the African continent, especially sub-Saharan Africa, where disaster management systems have either been non-existent or inadequate (Kapucu, 2014). In South Africa for example, the 2011 severe flooding throughout many parts of the country uncovered serious weaknesses in the country's disaster plans. Several lives were lost, thousands of homes were destroyed, and some US\$ 280 million in damage was caused (Nyakundi, et al., 2015). The disaster also highlighted additional problems like a lack of funding for proper management and the actual local and institutional capacity to carry out disaster management plans.

Kenya's disaster profile is dominated by droughts, fire, floods, terrorism, technological accidents, diseases and epidemics that disrupt people's livelihoods, destroy the infrastructure, divert planned use of resources, and interrupt economic activities and retard development (Ministry of State for Special Programmes, 2009). In the recent past fires, floods and collapsing of buildings have been the most rampant in urban centers in Kenya. Majority of these disasters could have been prevented or losses mitigated if proper disaster preparedness measures were in place. It is in this line that this study sought to establish the level of disaster preparedness for disaster risk management by rescue service teams in Nairobi County.

\subsection{Problem Statement}

As commonly understood, disaster implies a sudden misfortune causing extensive damage. Regardless of their origin and classification, all disasters have an importance due to their potential to cause loss of lives and livelihoods (Findley, 2012). What differs however is the preparedness of the community which determines its ability to cope and prevent loss of lives and livelihoods during the event and immediately after. It is even more important however, that the ability to predict a disaster before it happens allows mechanisms such as evacuations which drastically reduce loss of lives. While in developed countries governments, individuals and communities have greater capacities to deal with disasters, the economic losses are to some extent absorbed by a diversified economy and most assets are insured. Developing countries with limited economic diversity and poor infrastructure must not only rely on economic relief if a disaster occurs but their economies need more time to recover (UNDP, 2011) It is for this reason that the UN established UNOCHA in order for the latter to come up with clear statements, general principles and basic guidelines at international level, for eventual localization in the field of disaster prevention and mitigation through an integrated planning approach in developing countries (UNDP, 2013).

In the last two decades, Kenya has continued to face a rising degree of vulnerability to disaster risk. This risk is the probability of a hazard turning into a disaster, with households or communities being affected in such a manner that their lives and livelihoods are seriously disrupted beyond their capacity to cope or withstand using their own resources, with the result that affected populations suffer serious widespread human, material, economic or environmental losses (Nyakundi, et al., 2015). Communities are predisposed to disasters by a combination of factors such as poverty, aridity, settlement in areas prone to perennial flooding or areas with poor infrastructure and services such as the informal urban settlements or even living in poorly constructed buildings. The Kenya Government has in the face of increasing disasters taken several steps towards disaster mitigation and reduction. The government also formulated a National Disaster management policy in which disaster preparedness, mitigation, prevention measures and response mechanisms have been identified as important elements in effective disaster management (Republic of Kenya, 2004). It would be expected that a community that has lived through disaster would learn from the experience and thus be better prepared if faced with a similar situation. This study sought to establish the level of preparedness for disaster risk management by the rescue service teams in Nairobi County.

\subsection{General Objective}

The purpose of the study was to establish the level of disaster preparedness for disaster risk management by rescue service teams in Nairobi County.

\subsubsection{Specific Objectives}

- To establish the level of compliance to disaster management policies by rescue service teams in Nairobi County.

- To assess the availability of disaster management equipment by rescue service teams in Nairobi County.

- To determine the level of disaster management training being offered by rescue service teams in Nairobi County.

\section{Literature Review}

\subsection{Compliance to Disaster Management Policies}

Disaster management is often used in a general sense, covering the implementation of disaster preparedness, mitigation, emergency response and relief and recovery measures. A more general term 'disaster reduction or disaster risk reduction' is often used to mean the broad development and application of policies, strategies and practices to minimize vulnerabilities and disaster risks throughout society, through prevention, mitigation, and preparedness (Twigg, 2014). Public policy makers generally organize both research and guidance around four phases of disaster loss reduction: mitigation, preparedness, response, and recovery. 
On policy responses with regard to disaster preparedness in Africa, there have been no concerted regional efforts to manage disasters. Most of disaster responses initiatives in Africa have tended to focus on national and to a small extend sub-regional levels. Most of the efforts in Africa have actually concentrated on responses rather than mitigation (UNEP, 2002). Previous developmental policies and disaster planning, when applied to similar natural hazards in countries at various levels of development, produce a variety of results when disasters occur. In Kenya, The National Policy on Disaster Management emphasizes preparedness on the part of the government, communities and other stakeholders in disaster risk reduction activities. It aims to establish and strengthen disaster management institutions, partnerships, networking and mainstreaming of disaster risk reduction in the development process so as to improve the resilience of vulnerable groups to cope with potential disasters.

\subsection{Availability of Disaster Management Equipment}

Emergency response can be difficult to implement with limited materials, resources, equipment and time (Alexander, 2016). This makes equipment an equally important element of emergency preparedness. Equipment, which needs to be done at the preparedness phase, involves ensuring good service, supplies and facilities which can facilitate effective emergency response. The equipment element requires a reliable system of communications for response to emergencies which is effective within emergency organizations (Brito, 2012). Equipment is crucial because it helps to ensure that communication between and among emergency organizations and with the public are well understood and communicated. All mechanisms, facilities and procedures for operational response activities are expected to be organized before any incident occurs (Dillon, 2014).

Brito, (2012) states that equipment as an element of preparedness helps to determine the point of engagement as well as the vocal point of correspondence from where response arrangements will be coordinated, monitored, evaluated and mobilized, and this needs to be organized as stated in the emergency procedures in the response plan. This is key to effective and efficient organizing of facilities, resources and services required for responding to emergencies and ensuring the safety of the public. Equipping usually entails alerting signals, communication gadgets and information systems that can serve the response crew and the public. Essentially the equipment element involves the ability of the emergency sector to engage with the public through the media, with schools, private and public organizations, voluntary agencies and other institutions in order to make them aware of the risks they live with as well as prepare them for response to emergencies. According to Phillips (2015), the importance of being well equipped during the planning phase of an emergency can encourage the participation and involvement of the public in emergency management systems.

\subsection{Disaster Management Training}

Training of the stakeholders or partners in disaster management is very crucial. The importance of personnel training in disaster response cannot be overemphasized. In this area, assessment of applicable available courses is essential. The courses should be tailored to the needs of various disaster types and situations (Kanwar, 2008). The rationale behind this is that different disasters will need different types of health sector response and so is the personnel requirement. Thus, specialized courses in first aid, surgery, health education, etc. should be mounted to the health care personnel involved in disaster work. In addition, the training of trainers should be revitalized to meet the needs and emerging challenges of disasters. This should be done to all the various cadres and specialties of the personnel indulged in disaster operations. The trainers should be well versed with knowledge of current treatment and medical disaster response mechanisms to impart it to the trainees. In fact, it is only through this that we will have personnel who are effective and efficient in-service delivery in emergency situations.

Development of disaster management strategies and disaster mitigation projects training of staff in specialized fields of disaster management, capacity strengthening of the committees and sectoral departments in disaster management and responding to disasters (Gordon, 2004). The focus for training human service workers is on learning skills rather than knowledge, but knowledge is not ignored. According to Randolph, one emphasis of a disaster preparedness plan should be to anticipate the requirements for a disaster relief operation and the most effective ways of meeting those requirements. Training of those who will implement portions of the disaster preparedness plan is essential. Those responsible for issuing warnings must be trained as well as those who will have direct relief functions (Haddownand, 2006). Training cannot be a one-time event. Refresher courses are essential and training should be active in every way possible. Actual exercises should be performed such as evacuation drills. He specifically emphasizes on the need for training for those responding to a disaster situation, arguing that such training should be able to differentiate between speed and timeliness. According to Nicholson (2005), timeliness, not speed should be the preparedness criterion.

\section{Theoretical Framew ork}

The study was anchored on the decision theory. Decision theory acts as a guide to the analysis of behaviours for individuals faced with non-strategic uncertainty. This refers to the uncertainty due to what is termed as natural occurrence or where other individuals get involved, the uncertain behaviour of the decision maker. This theory is based upon the principles of the probability theory, formulated by Blaise Pascal, Daniel Bernoulli, and Thomas Bayes. Decision theory provides insights into the various forms of decision making and the decision outcomes expected. In relation to disaster management, decision theory postulate that due to the uncertain and risky nature of disasters affecting the society and necessitating participation of various individuals, organizations, sectors and stakeholders, partnership has a very vital role to play in the ultimate achievement of positive outcomes (Roe, et al., 2001).

Roe, et al., (2001) observed that it is likewise expected that different entities cooperate in a bid to enhance effectiveness and minimize fatalities. As far as decision making and partnership in disaster response is concerned, it is a 
tough job for societies to address. Persuasive discourse aligned to decision theory based on human behaviours show that individuals infringe on the principle of anticipated utility in a systematic way. This doesn't mean that individuals infringe upon preference consistency over the suitable choice but rather have incorrect beliefs derived from what is termed as "folk probability theory" and making systematic performance blunders in some cases (Levy, 2008).

When decisions are made by an agency or a coordinating body, it is critical to have comprehensive mechanism facilitating and enhancing decision-making processes through different structural, administrative, and behavioural changes (Raiffa, Richardson, \& Metcalfe, 2002). One unique feature of disasters is their character of lacking information in most instances. This uncertainty makes it hard to achieve disaster preparedness while the disaster response teams and inhabitants become susceptible to injury, disruption death, among other adverse effects of disasters occurrence. The peoples' perceptions, bureaucracy, and politics within the society which forms the basis of decision making among individuals within the society influences the society's disaster risk, susceptibility, resistance and resilience levels. Decision making for disaster preparedness therefore should adopt a contemporary approach and tools characterized by nonhierarchical structures and flexibility.

\section{Research Methodology}

\subsection{Research Design}

Cooper and Schindler, (2011) have defined research design terming it as research structure. The current study adopted descriptive survey as the research design guiding the study. The choice of this designed was informed by the fact that it is efficient in describing and reporting things as they are. Its fundamental feature is the collection of data systematically, mainly through questionnaires, from the targeted population (Ogula, 2015).

\subsection{Target Population}

The target population of this study comprised 1398 officers drawn from the National police officers, Paramedics, the fire brigade, the Red Cross society as well as officers from the interior ministry represented by the National Disaster management Unit (NDMU), county officers and consumers of the services because this population units were considered to be equipped with information that helped the researcher answer the research questions.

\subsection{Sampling Technique}

The research used stratified random sampling and simple random sampling. The sample population was segregated into two homogeneous groups (State actors and non-state actors) each consisting sub-groups i.e. state (police officers, the fire brigade, county officers and National Disaster management Unit (NDMU)) and non-state actors (the Paramedics, the consumers of the response and Red Cross society) from where the researcher randomly selected the respondents. Mugenda and Mugenda, (2009) observed that there are certain non-definite practices among social research workers that the beginner can adopt. One such practice suggests that if population is a few hundreds, a $40 \%$ or more samples will do: if many hundreds; a 20\% will do; and if several thousands, a 5\% or fewer samples will do. Accordingly, given the population of interest was estimated as 1398 respondents which was many hundreds, a sample size of 307 was used having added 10\% more to cater for non-response bias as recommended by Glenn (1992).

\begin{tabular}{|c|c|c|c|c|c|}
\hline Category & Team & Population(N) & $\mathbf{\%}$ & $\begin{array}{c}\text { Sample } \\
\text { Size(N) }\end{array}$ & Total \\
\hline \multirow{3}{*}{$\begin{array}{c}\text { Non-State } \\
\text { Actors }\end{array}$} & Red Cross & 118 & $20 \%$ & 24 & \\
\cline { 2 - 5 } & St.John's Ambulance & 85 & $20 \%$ & 17 & \multirow{2}{*}{$\begin{array}{c}279+10 \% \\
=307\end{array}$} \\
\cline { 2 - 5 } & Consumers of the response & 100 & $20 \%$ & 20 & \\
\hline State Actors & NDMU & 56 & $20 \%$ & 11 & \\
\cline { 2 - 5 } & Fire Brigade & 472 & $20 \%$ & 94 \\
\cline { 2 - 5 } & Police Officers & 557 & $20 \%$ & 111 & \\
\cline { 2 - 5 } & Senior County Officers & 10 & $20 \%$ & 2 & \\
\hline
\end{tabular}

Table 1: Proportionate Sample Size

\subsection{Data Collection}

The researcher used a structured questionnaire as the main data collection instrument. Questions were constructed so as to address specific objectives and provide a variety of possible responses. Franker, (2006) stated that a questionnaire is useful in obtaining objective data because participants are not manipulated in any way by the study. Questionnaires give the researcher comprehensive data on a wide range of factors. Both open-ended and closed-ended questions were used. The researcher recruited assistants who gave a hand in the field during the data collection.

\subsection{Data Processing and Analysis}

After the end of data collection, the process of data analysis immediately starts at which point the processing of data and interpretation starts (Kothari, 2013). The questionnaires from the field were therefore edited for consistency and completeness before processing the responses. The study generated quantitative and qualitative data. The analysis of 
quantitative data was through descriptive statistics after being coded and keyed into Statistical Packages for Social Scientists (SPSS Version 21). The study used measures of central tendency and dispersion, absolute and relative percentages, and frequencies for descriptive statistics. On the other hand, tables were used to present quantitative information whose explanations were done in prose.

\section{Research Results}

\subsection{Compliance to Disaster Management Policies}

On establishing the level of compliance to disaster management policies by rescue service teams in Nairobi County, the study sought respondents view on the extent to which the teams comply with the disaster management policies.

\begin{tabular}{|c|c|c|}
\hline Extent & Frequency & Percent \\
\hline Very great extent & 110 & 44 \\
\hline Great extent & 75 & 30 \\
\hline Moderate extent & 35 & 14 \\
\hline Little extent & 25 & 10 \\
\hline Not at all & 5 & 2 \\
\hline Total & 250 & 100 \\
\hline
\end{tabular}

Table 1: Extent to Which Rescue Teams Comply with the

Disaster Management Policies

From the study, $44 \%$ of the respondents indicated that the rescue teams comply with the disaster management policies to a very great extent, $30 \%$ of them indicated to a great extent, $14 \%$ of the respondents indicated that the rescue teams comply with the disaster management policies to a moderate extent, $10 \%$ of the respondents indicated to a little extent, while $2 \%$ of the respondents indicated that the rescue teams comply with the disaster management policies to no extent. The respondents were also required to indicate the extent to which the rescue teams considered various aspects of disaster management policies in their disaster preparedness approaches.

The results shown in Table 1.3 indicate that the rescue teams consider workplace rules are elements such as policies, processes, behaviors and employee attitudes to a great extent as shown by a mean score of 3.7744, development of rules and regulations to reduce disaster occurrences to a great extent as shown by a mean score of 3.6875 and institutional frameworks and planning to a great extent as shown by a mean score of 3.5489. They further reiterated that the rescue teams consider disaster risk reduction initiatives to a moderate extent as shown by a mean score of 3.2500 and policies for personnel notification to a moderate extent as shown by a mean score of 3.1203.

\begin{tabular}{|c|c|c|}
\hline Aspects of Disaster Management Policies in Disaster Preparedness & Mean & Std. Dev. \\
\hline Development of rules and regulations to reduce disaster occurrences & 3.6875 & 1.2500 \\
\hline Institutional frameworks and planning to & 3.5489 & 1.1772 \\
\hline Disaster risk reduction initiatives & 3.2500 & 0.67566 \\
\hline $\begin{array}{c}\text { Workplace rules are elements such as policies, processes, behaviors, and } \\
\text { employee attitudes }\end{array}$ & 3.7744 & 1.13228 \\
\hline Policies for personnel notification & 3.1203 & 1.10122 \\
\hline
\end{tabular}

Table 3: Aspects of Disaster Management Policies in Disaster Preparedness

Table 4 shows the extent to which various disaster management policies served various functions in disaster preparedness by the rescue service teams. On the extent to which the disaster management policies serve the various functions in disaster preparedness by rescue service teams in Nairobi County, majority of the respondents indicated that disaster management policies create awareness of disaster preparedness and long term mitigation to a great extent as shown by a mean score of 3.6875 and strengthen disaster management institutions to a great extent as shown by a mean score of 3.5000. They also indicated that disaster management policies mainstreaming of disaster risk reduction to a moderate extent as shown by a mean score of 3.2500, help vulnerable communities by developing coping mechanisms to a moderate extent as shown by a mean score of 3.2083 and improve the resilience of vulnerable groups to cope with potential disasters to a moderate extent as shown by a mean score of 3.1250 .

\subsection{Disaster Management Training}

The study sought to determine the level of disaster management training being offered by rescue service teams in Nairobi County. In this light, the respondents were requested to indicate the level of disaster management training for effective disaster preparedness among the rescue service teams. 


\begin{tabular}{|c|c|c|}
\hline Level of Training & Frequency & Percentage \\
\hline Very high level of training & 3 & 1 \\
\hline Highly trained & 152 & 61 \\
\hline Moderately trained & 45 & 18 \\
\hline Low level of training & 50 & 20 \\
\hline Not trained at all & 0 & 0 \\
\hline Total & 250 & 100 \\
\hline
\end{tabular}

Table 4: Level Disaster Management Training for Effective Disaster Preparedness

From the study, $61 \%$ of the respondents indicated that there was high level of disaster management training for effective disaster preparedness by rescue service teams in Nairobi County, $20 \%$ of them rated that the level of disaster management training for effective disaster preparedness by rescue service teams in Nairobi County was low, $18 \%$ of them rated it to be moderate, while only $1 \%$ of the respondents indicated that there is a very high level of disaster management training for effective disaster preparedness by rescue service teams in Nairobi County. Disaster management training through education and other information is informative and helpful in disaster preparedness. In the light of this statement, the study sought to establish the extent to which various areas of disaster management training were emphasized in disaster preparedness among the rescue service teams in Nairobi County.

\begin{tabular}{|c|c|c|}
\hline Disaster Management Training & Mean & Std. Dev. \\
\hline Courses in first aids & 3.3036 & 1.11060 \\
\hline Evacuation drills & 3.1429 & 1.10254 \\
\hline Informative forums on disaster management & 3.3036 & 1.18965 \\
\hline Establishment of First aid brigades & 3.9643 & .76192 \\
\hline Involvement of all stakeholders in disaster management training & 3.4643 & .91382 \\
\hline
\end{tabular}

Table 5: Disaster Management Training Areas Emphasized in Disaster Preparedness

From the study, establishment of first aid brigades was emphasized in disaster preparedness among the rescue service teams in Nairobi County to a great extent as shown by a mean score of 3.9643, involvement of all stakeholders in disaster management training was emphasized in disaster preparedness among the rescue service teams to a moderate extent as shown by a mean score of 3.4643, courses in first aids was emphasized to a moderate extent as shown by a mean score of 3.3036, informative forums on disaster management were also emphasized to a moderate extent as shown by a mean score of 3.3036 and evacuation drills were emphasized to a moderate extent as shown by a mean score of 3.1429.

\subsection{Disaster Management Equipment}

The study sought to assess the availability of disaster management equipment among rescue service teams in Nairobi County. As such the respondents were required to indicate how they would rate the level of disaster management equipment available for the rescue service teams in Nairobi County for effective disaster management. According to the results in Table 6, 42.0\% of the respondents rated the level of disaster management equipment available among rescue service teams in Nairobi County to be very high, $37 \%$ of them rated it to be high, $9 \%$ of the respondents rated the level of disaster management equipment available among rescue service teams in Nairobi County to be low, while $7 \%$ and $5 \%$ of them rated level of disaster management equipment available to be moderate and not at all respectively.

\begin{tabular}{|c|c|c|}
\hline Level & Frequency & Percent \\
\hline Very high & 105 & 42 \\
\hline High & 93 & 37 \\
\hline Moderate & 18 & 7 \\
\hline Low & 22 & 9 \\
\hline Not at all & 12 & 5 \\
\hline Total & 250 & 100 \\
\hline
\end{tabular}

Table 6: Level of Disaster Management Equipment

The respondents were further requested to indicate the extent to which various aspects of disaster management equipment determine the level of disaster preparedness by the rescue teams. 


\begin{tabular}{|c|c|c|}
\hline Aspects of Disaster Management Equipment & Mean & Std. Dev. \\
\hline Equipment of alarm systems (fire alarms, fire extinguishers,) & 3.9643 & 0.53815 \\
\hline Lifesaving facilities (first aid kits) & 3.8929 & 0.77878 \\
\hline Evacuation routes (Exit stairs, emergency doors) & 3.4643 & 0.91382 \\
\hline Assembly points (fire assembly points) & 3.7679 & 0.80884 \\
\hline
\end{tabular}

Table 7: Disaster Management Equipment in Determining the Disaster Preparedness

Majority of the respondents indicated that equipment of alarm systems (fire alarms and fire extinguishers) determine the level of disaster preparedness by the rescue teams to a great extent as shown by a mean score of 3.9643; lifesaving facilities (first aid kits) and assembly points (fire assembly points) also determine the level of disaster preparedness by the rescue teams to a great extent as shown by mean scores of 3.8929 and 3.7679 respectively, while evacuation routes (such as exit stairs, emergency doors) determine the level of disaster preparedness by the rescue teams to a moderate extent as shown by a mean score of 3.4643 .

\section{Conclusions}

- The study concludes that disaster management policies determine the extent to which the institutions are able to respond to various disasters. The compliance with the disaster management policies is a necessary step towards achieving better results in this area.

- The study further concludes that there is high level of disaster management training for effective disaster preparedness among rescue service teams in Nairobi County. Areas of focus of disaster management training include advocacy to raise stakeholders' awareness on the need to participate in disaster management.

- The study deduces that disaster management equipment influences the disaster preparedness in the institutions. The various aspects of disaster management include special internal arrangements for the acquisition and disbursement of funds, emergency funding strategies, policies and agreements for the use of other's equipment and services, and availability of disaster management equipment.

\section{Recommendations}

- The study recommends that there is need to enhance the disaster management policies in order to create awareness of disaster preparedness and long-term mitigation and strengthen disaster management institutions to great extents. As a consequence, disaster management policies will assist in mainstreaming of disaster risk reduction, help vulnerable communities by developing coping mechanisms and improve the resilience of vulnerable groups to cope with potential disasters.

- The study recommends that disaster responders seek to work towards addressing the realities of an oftenchanging environment and disaster management training should be undertaken continuously through the media, private sector and among other stakeholders.

- The study also recommends that the responders be adequately equipped with the necessary equipment for effective disaster management.

\section{References}

i. Alexander, D. (2016). Globalization of disaster: trends, problems and dilemmas. Journal of International Affairs, 78(2): 1-22.

ii. Brito,J. (2012). Sending out an S.O.S.: public safety communications interoperability as a collective action problem. Washington : Mercatus Publications.

iii. Cooper, D. R., \& Schindler, P. S. (2011). Business Research Methods (8th edn). New York: McGraw-Hill.

iv. Dillon, B. (2014). Blackstone's Emergency Planning, Crisis and Disaster Management. Oxford : 2nd Ed, Oxford University Press.

v. Findley, D. (2012). Improvisation during disaster response. Emergency Management Review. Journal of the Emergency Planning Society, 1 (1) 2012.

vi. Franker (2006). Understanding the Research Process and Methods: An Introduction to Research Methods. Chicago: John Wiley and Sons.

vii. Glenn, D. (1992). Sampling the evidence of extension program impact. Program Evaluation and Organizational Development, IFAS, University of Florida.

viii. Gordon, P. (2004). The Convergence of Contingency Planning, Emergency Management, and Homeland Security. CPM Global Assurance.

ix. Halimu, S. S. (2017). Social services in disaster situations in Kenya. Sociological Spectrum 13: 175- 192.

x. Kanwar, S., (2008) Local Level Coordination: Good Practices and Tools from the Tsunami Response and Recovery Experience in Tamil Nadu, India, UNDP, New Delhi.

xi. Kapucu, N. (2014). Interagency Communication Networks During Emergencies: Boundary Spanners in Multiagency Coordination. The American Review of Public Administration, 48(2), 207-225.

xii. Kothari, C. R. (2013). Research Methodology: Methods \& Techniques (2nd ed.). Delhi:: New Age International Ltd.

xiii. Mugenda, M. O., \& Mugenda, A. (2009). Research Methods: Qualitative and Quantitative Approaches,. Nairobi, Kenya.: African Centre for Technology Studies. 
xiv. Nicholson, W.C. (2005). NFPA 1600: The New Standard for Emergency Management. Journal of Emergency Management. 3(2): 44-46.

xv. Nyakundi, H., Mogere, S., Mwanzo, I., \& Yitambe, A. (2015). Community perceptions and response to flood risks in Nyando district, Western Kenya.Jàmbá J Disaster Risk Studies, 3:346-66.

xvi. $\quad$ Ogula, P. A. (2015). Research Methods. Nairobi:: CUEA Publications.

xvii. Paul, C. S. (2012). The Ellis Park Disaster Interim Report: A Synopsis and Commentary. The International Sports Law Journal, 3, 13 - 17.

xviii. Phillips, B. D. (2015). Disaster as a Discipline: The Status of Emergency Management Education in the US. International Journal of Mass-Emergencies and Disasters, Vol. 30 (1): 111-140.

xix. Quarantelli, E. L. (2010). Emergent behaviors and groups in the crisis time of disasters. Pp. 47-68 in Kian M. Kwan (ed.) Individuality and Social Control: Essays in Honor of Tamotsu Shibutani. Greenwich, CT.: JAI Press.

xx. Raiffa, H., Richardson, J., \& Metcalfe, D. (2002). Negotiation analysis: The science and art of collaborative decisionmaking. Cambridge, MA: Harvard University Press.

xxi. $\quad$ Roe, R. M., Busemeyer, J. R., \& Townsend, J. T. (2001). Multi-alternative decision field theory: A dynamic connectionist model of decision making. Psychological Review, 108(2), 370-392.

xxii. Twigg, J. (2014). Lessons from Disaster Preparedness. Notes for presentation to Workshop 3: It Pays to Prepare at International Conference on Climate Change and Disaster Preparedness, 26-28 June 2002, The Hague, Netherlands.

xxiii. UN (2012). United Nations International Strategy for Disaster Reduction Secretariat (UNISDR). Geneva: UN.

xxiv. UNDP (2011). Disaster Profiles of the Least Developed Countries. Geneva, United Nations Development Programme Emergency Response Division

xxv. UNDP (2013). Human Development Report 2013, Millennium Development Goals A Compact Among Nations to End Human Poverty. New York, USA.

xxvi. UNEP (2002). A Rapid Assessment of the Impacts of the Iraq-Kuwait Conflict on Terrestrial Ecosystems: Part II - the State of Kuwait. Manama, Bahrain, UNEP Regional Office for West Asia 